\title{
Synthesis and Characterization of a Metal-Organic Framework Bridged by Long Flexible Ligand
}

\author{
Kawther Osman Ashiry ${ }^{1,2}$, Rasha Khalid Abbas ${ }^{1,3}$ \\ ${ }^{1}$ Department of Chemistry, Faculty of Science and Arts in Mukhwa, University of Albaha, Albaha, Saudi Arabia \\ ${ }^{2}$ Department of Chemistry, Faculty of Science, University of Bahri, Al-Khartoum, Sudan \\ ${ }^{3}$ Department of Biochemistry, Faculty of Applied and Industrial Science University of Bahri, Al-Khartoum, Sudan \\ Email: kawtherashiry@yahoo.com,rashakhalid09@gmail.com
}

How to cite this paper: Ashiry, K.O. and Abbas, R.K. (2021) Synthesis and Characterization of a Metal-Organic Framework Bridged by Long Flexible Ligand. Open Journal of Polymer Chemistry, 11, 1-9. https://doi.org/10.4236/ojpchem.2021.1110 $\underline{01}$

Received: December 19, 2020

Accepted: February 23, 2021

Published: February 26, 2021

Copyright $\odot 2021$ by author(s) and Scientific Research Publishing Inc. This work is licensed under the Creative Commons Attribution International License (CC BY 4.0).

http://creativecommons.org/licenses/by/4.0/

\begin{abstract}
3D supramolecular network with considerable volume pores was created via hydrogen bond \& C-H-- $\pi$. By tightening of The metal-organic frameworks (MOF) namely $\left[\mathrm{Ni}(\mu \text {-pmb })_{2}\left(\mathrm{H}_{2} \mathrm{O}\right)_{2}\right]_{\mathrm{n}}$ (pmb $=3,5$-bis(4-pyridylmethylenoxyl) benzoate, that have been synthesized by hydrothermal method. Complex 1 crystallizes in triclinic P-1 space group and consists of $1 \mathrm{D}$ semi zigzag chain.
\end{abstract}

\section{Keywords}

Coordination Polymer, Hydrogen Bond, Metal-Organic Frameworks, Ligand

\section{Introduction}

In recent years, the area of inorganic-organic open framework materials has become one of the intense research activity [1]-[7] not only for the intellectual challenge in controlling and manipulating the self-assembly process but also for their fascinating structural diversities and potential applications in catalysis, molecular adsorption, magnetism, nonlinear optics and molecular sensing [8]-[13]. By closely controlling the properties of the ligands such as the shape [14] [15], functionality [16] [17], flexibility [18] [19], conformation [20] [21], and symmetry [22] [23], frameworks with fantastic structures and desirable properties can be created. Multidentate $\mathrm{N}$ or $\mathrm{O}$ donor ligands have been extensively employed in the construction of extended structures, such as the flexible ligands 1,2-bis (4pyridyl)ethane (bpe) [24] [25], and its analogues [26] [27], which can adopt the gauche and anti-conformations. Metal-organic frameworks (MOFs) constructed by mixing pyridyl and carboxylate groups are applicable for the reason 
that it incorporates the interesting properties of the different functional groups [28]. It has been well recognized that the noncovalent intermolecular forces such as hydrogen bond interactions are reasonably strong [29] [30] and can be used as structural-directing tools in generating many molecular solids with novel properties [31] [32]. Incorporation of both metal-ligand covalent bonds and hydrogen bonds to control the arrangement of the molecule in the space has been considered one of the most rational design strategies. Taking account of all above depicted points, we have employed a long flexible ligand 3,5-bis(4-pyridylmethylenoxyl)benzoate to construct a coordinated infinite framework, formulated as

$$
\left[\mathrm{Ni}(\mu-\mathrm{pmb})_{2}\left(\mathrm{H}_{2} \mathrm{O}\right)_{2}\right]_{\mathrm{n}}
$$

\section{Experimental}

\subsection{General}

All chemicals purchased were of reagent grade and used without further purification. Elemental analyses $(\mathrm{C}, \mathrm{H}$, and $\mathrm{N})$ were performed on a Perkin-Elmer $2400 \mathrm{CHN}$ Elemental Analyzer. FT-IR spectra were recorded in the range 400 $4000 \mathrm{~cm}^{-1}$ on an Alpha Centaurt FT/IR Spectrophotometer as $\mathrm{KBr}$ pellets. The emission/excitation spectra were recorded on a Varian Cary Eclipse spectrometer. TGA experiments were performed from room temperature to $700^{\circ} \mathrm{C}$ using a Perkin-Elmer TG-7 analyzer under nitrogen at a heating rate of $10^{\circ} \mathrm{C} / \mathrm{min}$.

\subsection{Synthesis of 3,5-PMB}

3,5-dihydroxybenzoic acid ( $15.4 \mathrm{~g}$ ), ethanol $(53 \mathrm{ml})$, and sulphuric acid $(4 \mathrm{ml})$ were mixed and refluxed for $6-7 \mathrm{~h}$. The excess ethanol was removed under vacuum, and then extracted by ethylacetate. The extracted solution was washed by water for one time, and an other time by $\mathrm{NaHCO}_{3}$, after drying by $\mathrm{Na}_{2} \mathrm{SO}_{4}$ the solvent was evaporated. To $20 \mathrm{mmol}$ (3.64 g) of the product, $40 \mathrm{mmol}(6.5 \mathrm{~g})$ of 4-pycolyl chloride hydrochloride and $120 \mathrm{mmol}(4.8 \mathrm{~g}) \mathrm{of} \mathrm{NaOH}$ and $10 \mathrm{mls}$ DMF were added, the mixture was heated at $70^{\circ} \mathrm{C}$ for $10 \mathrm{~h}$., then the product was washed by ethanol and filtered. The solid product was transferred to $100 \mathrm{ml}$ round bottom flask, $50 \mathrm{ml}$ of $5 \% \mathrm{NaOH}$ solution was added and refluxed under $70^{\circ} \mathrm{C}$ for 5 hours, after transferred into $400 \mathrm{ml}$ beaker, $50 \mathrm{ml}$ of distilled water was added, then concentrated HCL was added drop by drop, at $\mathrm{pH}=6$, light brown precipitate was obtained, washed by ethanol and filtered. Yield: $72 \%$. Calcd (\%) for $\mathrm{C}_{19} \mathrm{H}_{16} \mathrm{~N}_{2} \mathrm{O}_{4}$ (336.11): C, 67.85; H, 4.79; N, 8.33\%. Found: C, 67.91; $\mathrm{H}, 4.98 ; \mathrm{N}, 8.2$.

\subsection{Synthesis of $\left[\mathrm{Ni}(\mu 3,5-\mathrm{PMB})_{2}\left(\mathrm{H}_{2} \mathrm{O}\right)_{2}\right]_{\mathrm{n}}(1)$}

A mixture of $\mathrm{NiCl}_{2} \cdot 6 \mathrm{H}_{2} \mathrm{O}(0.030 \mathrm{mmol}, 0.072 \mathrm{~g})$, pmb $(0.20 \mathrm{mmol}, 0.073 \mathrm{~g})$, $\mathrm{NaOH}(0.6 \mathrm{mmol} 0.024 \mathrm{~g})$ and $(8 \mathrm{ml})$ distilled water was heated in sealed Teflon lined steal at $150^{\circ} \mathrm{C}$ for three days, then cooled to room temperature at a rate of $10^{\circ} \mathrm{C} / \mathrm{h}$. Green block crystals were obtained. Yield: $54 \%$. Elemental analysis calcd 
(\%) for $\mathrm{C}_{38} \mathrm{H}_{34} \mathrm{~N}_{4} \mathrm{O}_{14} \mathrm{Ni}$ (829.39): C, 55.03; H, 4.13; N, 6.76\%. Found: C, 54.98; H, $4.09 ; \mathrm{N}, 6.72 .6$.

\subsection{X-Ray Crystallography}

Suitable single crystal with approximate dimensions $0.31 \times 0.26 \times 0.24 \mathrm{~mm}(1)$, was mounted on a glass fiber and used for X-ray diffraction analyses. Data were collected at 293(2) $\mathrm{K}$ on a Bruker ApexII CCD diffractometer using the $\omega$ scan technique with Mo K $\alpha$ radiation $(K=0.71069 \AA)$. Absorption corrections were applied using the multi-scan technique [33]. The structures were solved by the Direct Method and refined by full-matrix least-square techniques on F2 using SHLXL-97 [34].

\section{Result and Discussion}

Complexes 1 were successfully synthesized hydrothermslly. In a typical procedure for synthesizing 1 , a mixture of $\mathrm{NiCl}_{2} \cdot 6 \mathrm{H}_{2} \mathrm{O}, \mathrm{pmb}$ and $\mathrm{NaOH}$ in a ratio of 1:2/3:2/3:2 was used.

\subsection{Description of Crystal Structure}

A summary of crystal data, experimental details and refinement results for compounds $1-2$ are listed in Table 1. Selected bond lengths and angles for $1-2$ are given in Table 2 Complex 1 crystallizes in the triclinic space group P-1 with a formula $\left[\mathrm{Ni}(\mu-\mathrm{pmb})_{2}\left(\mathrm{H}_{2} \mathrm{O}\right)_{2}\right]_{\mathrm{n}}$. The asymmetric unit contains one central $\mathrm{Ni}$ atom, two pmb ligands and two water molecules as shown in Figure 1. The $\mathrm{Ni}$ atom is six-coordinated by tw oxygen atoms of different carboxylate groups from two pmb ligands with $\mathrm{Ni}-\mathrm{O}(1)=2.05 \AA$ and two nitrogen atoms of different pmb in a distance of $2.116 \AA$ and two oxygen atoms of different water molecules $(\mathrm{Ni}-\mathrm{O}(3)=2.094 \AA$ ), to form a distorted octahedral geometry. Adjacent $\mathrm{Ni}$ atoms are linked by two pmb ligands to form a neutral 1D zigzag polymeric chain spanning along the a-axis (Figure 2). The distance between each two neighboring $\mathrm{Ni}$ atoms intersecting the circuit made by two pmb moieties is $11.979 \AA$ A. The uncoordinated pyridyl rings are oriented up- or down-side with respect to the $\mathrm{Ni}$ atom in the apexes of the zigzag chain, this orientation plays an important role in the packing into a higher network through hydrogen bonding interactions. It should be mentioned that adjacent chains recognize each other through the very short hydrogen bond between the oxygen atom of water molecule in the chain and the nitrogen of pyridyl ring in the adjacent chain (bond length is $2.77 \AA$ and oxygen atoms of different carboxylate groups from two pmb ligands with $\mathrm{Ni}-\mathrm{O}(1)=2.05 \AA$ and twonitrogen atoms of different pmb in a distance of $2.116 \AA$ and two oxygen atoms of different watermolecules $(\mathrm{Ni}-\mathrm{O}(3)=$ $2.094 \AA$ ), to form a distorted octahedral geometry. Adjacent Ni atoms are linked by two pmb ligands to form a neutral $1 \mathrm{D}$ zigzag polymeric chain spanning along the a-axis (Figure 2). The distance between each two neighboring $\mathrm{Ni}$ atoms intersecting the circuit made by two pmb moieties is $11.979 \AA$. The uncoordinated 
Table 1. Crystalographic data for complexes 1.

\begin{tabular}{|c|c|}
\hline Parameter & 1 \\
\hline Emprical formula & $\mathrm{C}_{38} \mathrm{H}_{34} \mathrm{~N}_{4} \mathrm{O}_{14} \mathrm{Ni}$ \\
\hline$T(K)$ & $293(2)$ \\
\hline Wavelength $(\AA)$ & 0.71069 \\
\hline Crystal system & Triclinic \\
\hline Space group & P-1 \\
\hline$a(\AA)$ & $18.796(5)$ \\
\hline$b(\AA)$ & $10.121(5)$ \\
\hline$c(\AA)$ & $20.513(5)$ \\
\hline$\alpha$ & $90.000(5) \mathrm{deg}$. \\
\hline$\beta$ & 98.312(5) deg. \\
\hline$\gamma$ & $90.000(5) \mathrm{deg}$. \\
\hline$V\left(\AA^{3}\right)$ & $3861(2)$ \\
\hline$Z$ & 4 \\
\hline$D_{\text {calc }}\left(m g \cdot m^{-3}\right)$ & 1.427 \\
\hline Absorption coefficient $\left(\mathrm{mm}^{-1}\right)$ & 0.576 \\
\hline$F(000)$ & 1720 \\
\hline Crystal size $(\mathrm{mm})$ & $0.31 \times 0.26 \times 0.24$ \\
\hline$\theta$ (Range of data collection) & 2.01 to $28.27 \mathrm{deg}$. \\
\hline \multirow[t]{3}{*}{ Limiting indices } & $-22 \leq \mathrm{h} \leq 24$ \\
\hline & $-13 \leq \mathrm{k} \leq 11$ \\
\hline & $-26 \leq 1 \leq 26$ \\
\hline $\operatorname{Data}[1>2 \sigma(1)]$ & $4667 / 0 / 266$ \\
\hline Goodnes of fit on $F^{2}$ & 0.943 \\
\hline$R_{1,}, w R_{2}$ indices $(1>2 \sigma(1))^{a}$ & $R_{1}=0.0517, w R_{2}=0.1396$ \\
\hline$R_{1}, w R_{2}$ (all data) & $R_{1}=0.0747, w \mathrm{R}_{2}=0.1544$ \\
\hline
\end{tabular}

Table 2. Selected bond length $(\AA)$ and angles $\left({ }^{\circ}\right)$ for complexes 1 .

\begin{tabular}{cccc}
\hline & \multicolumn{3}{c}{1} \\
\hline $\mathrm{Ni}(1)-\mathrm{O}(1)$ & $2.0511(17)$ & $\mathrm{Ni}(1)-\mathrm{O}(1) \# 1$ & $2.0511(17)$ \\
$\mathrm{Ni}(1)-\mathrm{O}(3) \# 1$ & $2.093(2)$ & $\mathrm{Ni}(1)-\mathrm{O}(3)$ & $2.093(2)$ \\
$\mathrm{Ni}(1)-\mathrm{N}(1) \# 1$ & $2.115(2)$ & $\mathrm{Ni}(1)-\mathrm{N}(1)$ & $2.115(2)$ \\
$\mathrm{O}(1)-\mathrm{Ni}(1)-\mathrm{O}(1) \# 1$ & $175.25(9)$ & $\mathrm{O}(1)-\mathrm{Ni}(1)-\mathrm{O}(3) \# 1$ & $87.36(8)$ \\
$\mathrm{O}(1) \# 1-\mathrm{Ni}(1)-\mathrm{O}(3) \# 1$ & $89.48(8)$ & $\mathrm{O}(1)-\mathrm{Ni}(1)-\mathrm{O}(3)$ & $89.48(8)$ \\
$\mathrm{O}(1) \# 1-\mathrm{Ni}(1)-\mathrm{O}(3)$ & $87.36(8)$ & $\mathrm{O}(3) \# 1-\mathrm{Ni}(1)-\mathrm{O}(3)$ & $96.47(13)$ \\
$\mathrm{O}(1)-\mathrm{Ni}(1)-\mathrm{N}(1) \# 1$ & $90.81(7)$ & $\mathrm{O}(1) \# 1-\mathrm{Ni}(1)-\mathrm{N}(1) \# 1$ & $92.66(8)$ \\
$\mathrm{O}(3) \# 1-\mathrm{Ni}(1)-\mathrm{N}(1) \# 1$ & $88.76(10)$ & $\mathrm{O}(3)-\mathrm{Ni}(1)-\mathrm{N}(1) \# 1$ & $174.77(9)$ \\
$\mathrm{O}(1)-\mathrm{Ni}(1)-\mathrm{N}(1)$ & $92.66(8)$ & $\mathrm{O}(1) \# 1-\mathrm{Ni}(1)-\mathrm{N}(1)$ & $90.81(7)$ \\
$\mathrm{O}(3) \# 1-\mathrm{Ni}(1)-\mathrm{N}(1)$ & $174.77(9)$ & $\mathrm{O}(3)-\mathrm{Ni}(1)-\mathrm{N}(1)$ & $88.76(10)$ \\
$\mathrm{N}(1) \# 1-\mathrm{Ni}(1)-\mathrm{N}(1)$ & $86.02(13)$ & & \\
\hline Symmetry codes: for $1 \# 1-x+1, y,-z+3 / 2 ; \# 2 x,-y+1, z-1 / 2 ; \# 3 x,-y+1, z+1 / 2 ;$ for $2 \# 1-x+1, y$, \\
$-z+3 / 2 ; \# 2-x+1,-y,-z+2 ; \# 3 x, y-1, z ; \# 4 x, y+1, z$.
\end{tabular}




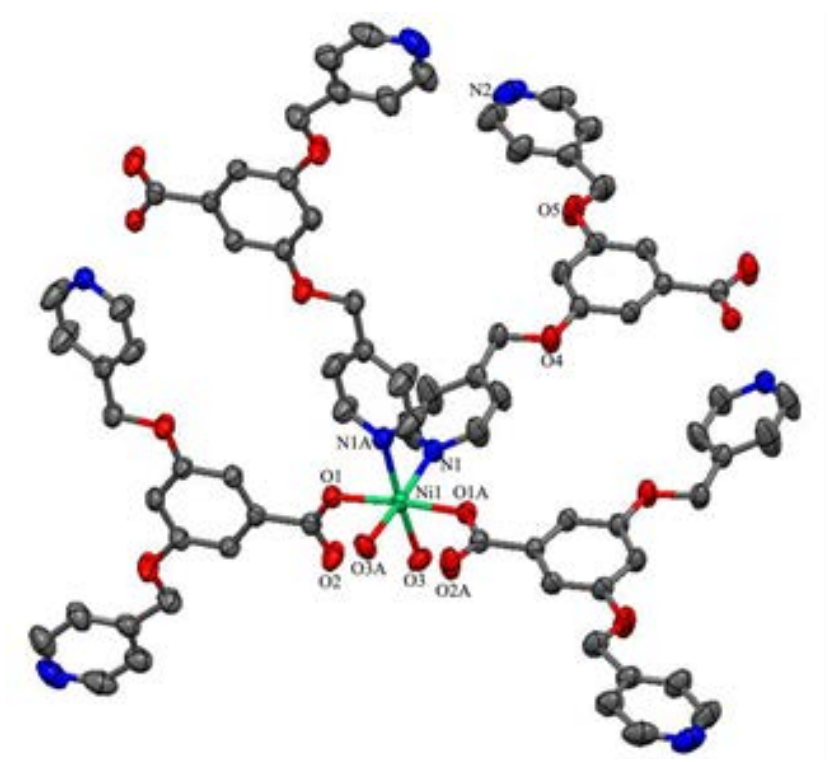

Figure 1. ORTEP view of 1 showing the coordination environment of the Ni center $(50 \%$ probability level).

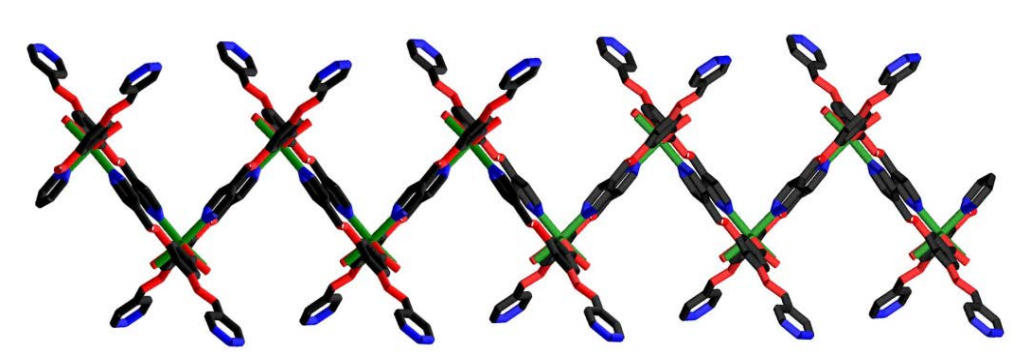

Figure 2 . The neutral $1 \mathrm{D}$ zigzag polymeric chain spanning along the a-axis in 1 .

pyridyl rings are oriented up- or down-side with respect to the $\mathrm{Ni}$ atom in the apexes of the zigzag chain, this orientation plays an important role in the packing into a higher network through hydrogen bonding interactions. It should be mentioned that adjacent chains recognize each other through the very short hydrogen bond between the oxygen atom of water molecule in the chain and the nitrogen of pyridyl ring in the adjacent chain (bond length is $2.77 \AA$ and $\mathrm{N}-\mathrm{H} \cdots \mathrm{O}$ angle is $152.67^{\circ}$ ) (Figure $3(\mathrm{a})$ ), and $\mathrm{C}-\mathrm{H} \cdots \pi$ interaction between the phenyl ring and the hydrogen of pyridyl ring. These interactions are of lengths vary between $3.2-3.6 \AA$. .). The angle between the coordinated water molecules $(\mathrm{O}(3)-\mathrm{Ni}-\mathrm{O}(3))$ is $96.47^{\circ}$, so the extension via hydrogen bond interactions occurs in the $\mathrm{b}$ and c-axis converting the $1 \mathrm{D}$ zigzag chain into a three dimensional network with rectangular grid of dimensions $=12.06 \times 17.85 \AA$ parallel to the ab-plane (Figure $3(b))$. It is interesting to note that despite the presence of such large sized voids no interpenetration is observed.

\subsection{IR Spectra}

The IR spectra of complex 1 show the absorption bands of the skeletal vibrations of the aromatic rings appear in the $1616-1382 \mathrm{~cm}^{-1}$ region and strong broa- 
dened band at $3414 \mathrm{~cm}^{-1}$ due to the presence of water ligands [35].

\subsection{Compositional Stability of the New MOFs}

To estimate the stability of the supramolecular architecture, thermogravimetric analyses experiments of complexe 1 was carried out in the temperature range of $50^{\circ} \mathrm{C}-900^{\circ} \mathrm{C}$. As shown in (Figure 4), the framework of complex 1 is stable up

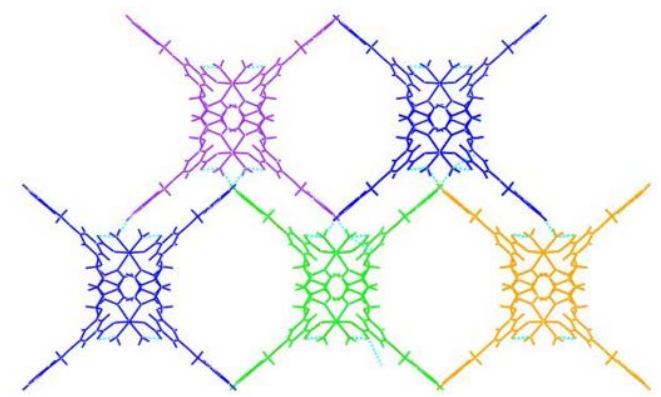

(a)

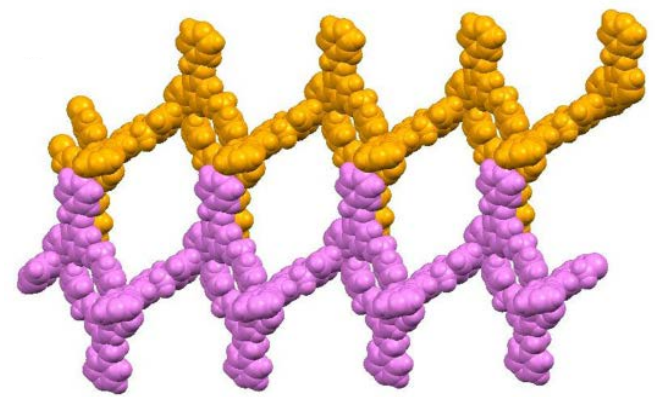

(b)

Figure 3. (a) The extension in b and c direction via hydrogen bond shown as blue dots. (b) Rectangular void generated by hydrogen bonding and $\mathrm{C}-\mathrm{H} \cdots \pi$ interactions.

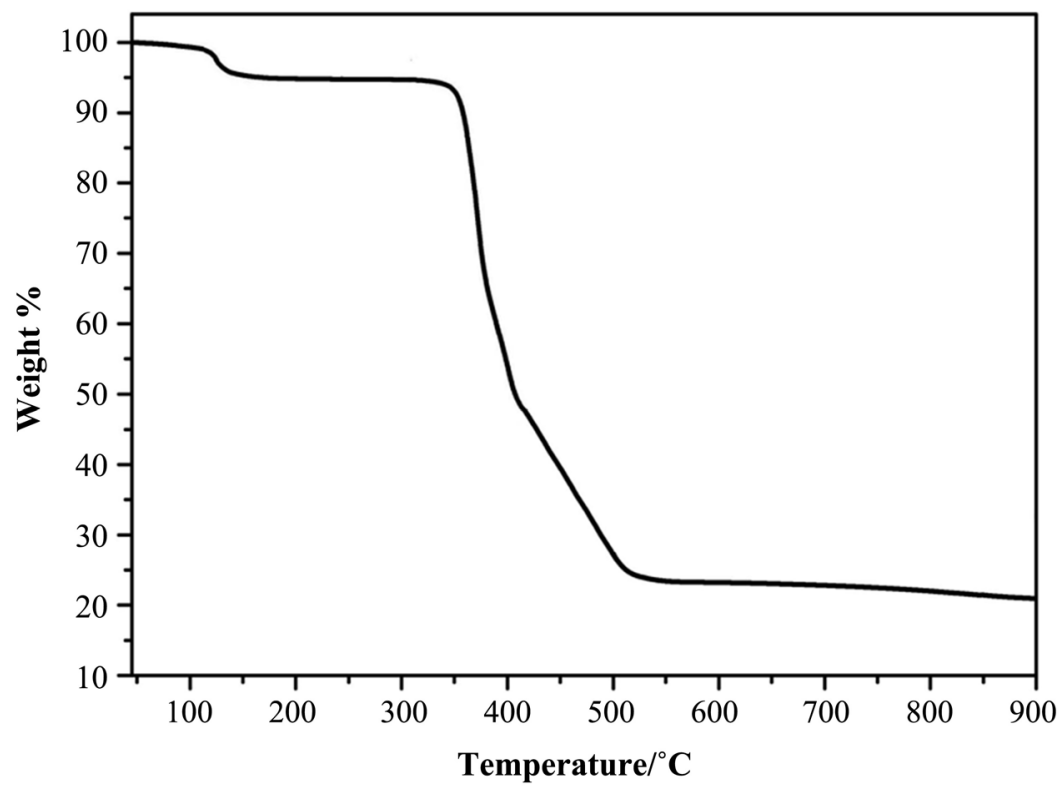

Figure 4. TGA curve for comp. 
to $358^{\circ} \mathrm{C}$. A rapid weight loss can be detected from $358^{\circ} \mathrm{C}$ to $510^{\circ} \mathrm{C}$. That is attributed to the complete decomposition of the organic ligands.

\section{Conclusion}

In conclusion, novel MOF has been successfully synthesized and fully structurally characterized by using the flexible 3,5-bis(4-pyridylmethylenoxyl)benzoate ligand and incorporating binary aromatic acid as co-ligands under the same hydrothermal conditions. Complex 1 exhibits $1 \mathrm{D}$ zigzag chain converted via hydrogen bond to 3D supramolecular framework with locked rectangle.

\section{Conflicts of Interest}

The authors declare no conflicts of interest regarding the publication of this paper.

\section{References}

[1] Barrer, R.M. (1982) Hydrothermal Chemistry of Zeolite. Academic Press, London.

[2] Occelli, M.L. and Robson, H.C. (1989) Zeolite Synthesis. American Chemical Society, Washington DC. https://doi.org/10.1021/bk-1989-0398

[3] Cheethman, A.K., Ferey, G. and Loiseau, T. (1999) Open-Framework Inorganic Materials. Angewandte Chemie International Edition, 38, 3268-3292.

https://doi.org/10.1002/(SICI)1521-3773(19991115)38:22<3268::AID-ANIE3268>3. $\underline{0 . \mathrm{CO} ; 2-\mathrm{U}}$

[4] Weller, M.T. and Dann, S.E. (1998) Hydrothermal Synthesis of Zeolites. Current Opinion in Solid State \& Materials Science, 3, 137-143. https://doi.org/10.1016/S1359-0286(98)80078-8

[5] Muller, A., Reuter, H. and Dillinger, S. (1995) Supramolecular Inorganic Chemistry: Small Guests in Small and Large Hosts. Angewandte Chemie International Edition, 34, 2311.

[6] Hagrman, P.J., Hagrman, D. and Zubieta, J. (1999) Organic-Inorganic Hybrid Materials: From "Simple" Coordination Polymers to Organodiamine-Templated Molybdenum Oxides. Angewandte Chemie International Edition, 38, 2638-2684. https://doi.org/10.1002/(SICI)1521-3773(19990917)38:18<2638::AID-ANIE2638>3. $\underline{0 . \mathrm{CO} ; 2-4}$

[7] Rao, C.N.R. (2004) Metal Carboxylates with Open Architectures. Angewandte Chemie International Edition, 43, 1466-1496. https://doi.org/10.1002/anie.200300588

[8] Seo, J.S., Wang, D., Lee, H., Jun, I., Oh, J., Jeon, Y.J. and Kim, K. (2000) A Homochiral Metal-Organic Porous Material for Enantioselective Separation and Catalysis. Nature (London), 404, 982-986. https://doi.org/10.1038/35010088

[9] Lin, W., Evans, O.R., Xiong, R.G. and Wang, Z.J. (1998) Supramolecular Engineering of Chiral and Acentric 2D Networks. Synthesis, Structures, and Second-Order Nonlinear Optical Properties of Bis(nicotinato)zinc and Bis\{3-[2-(4-pyridyl)ethenyl]benzoato\}cadmium. Journal of the American Chemical Society, 120, 13272 13273. https://doi.org/10.1021/ja983415h

[10] Pang, J.E., Marcotte, J.P., Seward, C., Brown, R.S. and Wang, S.N. (2001) A Blue Luminescent Star-Shaped $\mathrm{Zn}^{\mathrm{II}}$ Complex that Can Detect Benzene. Angewandte Chemie International Edition, 40, 4042-4045. 
https://doi.org/10.1002/1521-3773(20011105)40:21<4042::AID-ANIE4042>3.0.CO;2 $-0$

[11] Inoue, K., Imai, H., Ghalsasi, P.S., Kikuchi, K., Ohba, M., Okawa, H. and Yakhmi, J.V. (2001) A Three-Dimensional Ferrimagnet with a High Magnetic Transition Temperature (TC) of $53 \mathrm{~K}$ Based on a Chiral Molecule. Angewandte Chemie International Edition, 40, 4242-4245.

https://doi.org/10.1002/1521-3773(20011119)40:22<4242::AID-ANIE4242>3.0.CO;2 $\underline{-\mathrm{H}}$

[12] Cave, D.J., Gascon, M., Bond, A.D., Teat, S.J. and Wood, P.T. (2002) Layered Metal Organosulfides: Hydrothermal Synthesis, Structure and Magnetic Behaviour of the Spin-Canted Magnet Co(1,2-(O2C)(S)C6H4). Chemical Communications, 1050-1051. https://doi.org/10.1039/b111339a

[13] Wang, X., Qin, C., Wang, E., Li, Y., Hao, N., Hu, C. and Xu, L. (2004) Syntheses, Structures, and Photoluminescence of a Novel Class of $\mathrm{d}^{10}$ Metal Complexes Constructed from Pyridine-3,4-dicarboxylic Acid with Different Coordination Architectures. Inorganic Chemistry, 43, 1850-1856. https://doi.org/10.1021/ic035151s

[14] Dong, Y.B., Cheng, J.Y., Huang, R.Q., Smith, M.D. and Zur Loye, Y.B. (2003) Self-Assembly of Coordination Polymers from AgX (X = SbF6-, PF6-, and CF3SO3-) and Oxadiazole-Containing Ligands. Inorganic Chemistry, 42, 5699.

[15] Galan-Mascaros, J.R. and Dunbar, K.R. (2003) A Self-Assembled 2D Molecule-Based Magnet: The Honeycomb Layered Material $\{\mathrm{Co} 3 \mathrm{Cl} 4(\mathrm{H} 2 \mathrm{O}) 2[\mathrm{Co}(\mathrm{Hbbiz})$ 3]2\}. Angewandte Chemie International Edition, 42, 2289-2293. https://doi.org/10.1002/anie.200250152

[16] Cui, Y., Lee, S.J. and Lin, W.J. (2003) Interlocked Chiral Nanotubes Assembled from Quintuple Helices. Journal of the American Chemical Society, 125, 6014-6015. https://doi.org/10.1021/ja029926s

[17] Horikoshi, R., Mochida, T. and Moriyama, H. (2002) Synthesis and Characterization of Redox-Active Coordination Polymers Generated from Ferrocene-Containing Bridging Ligands. Inorganic Chemistry, 41, 3017-3024.

https://doi.org/10.1021/ic011176k

[18] Chen, L.C., Su, C.Y., Cai, Y.P., Zhang, H.X., Xu, A.W., Kang, B.S. and Zur, H.C. (2003) Multidimensional Frameworks Assembled from Silver(I) Coordination Polymers Containing Flexible Bis(thioquinolyl) Ligands: Role of the Intra- and Intermolecular Aromatic Stacking Interactions. Inorganic Chemistry, 42, 3738-3750. https://doi.org/10.1021/ic0341035

[19] Bu, X.H., Hou, W.F., Du, M., Chen, W.R. and Zhang, H. (2002) Varying the Frameworks of Novel Silver(I) Coordination Polymers with Thioethers by Altering the Backbone or Terminal Groups of Ligands. Crystal Growth \& Design, 2, 303-307. https://doi.org/10.1021/cg025510e

[20] Khlobystor, A.N., Blake, A.J., Champness, N.R., Lemenovskii, D.A., Majouga, A.G., Zyk, N.V. and Schröder, M. (2001) Supramolecular Design of One-Dimensional Coordination Polymers Based on Silver(I) Complexes of Aromatic Nitrogen-Donor Ligands. Coordination Chemistry Reviews, 222, 155-192. https://doi.org/10.1016/S0010-8545(01)00370-8

[21] Hirsch, K.A., Wilson, S.R. and Moore, J.S. (1997) Coordination Networks of 3,3'-Dicyanodiphenylacetylene and Silver(I) Salts: Structural Diversity through Changes in Ligand Conformation and Counterion. Inorganic Chemistry, 36, 2960-2968. https://doi.org/10.1021/ic970150j

[22] Masood, M.A., Enemark, E.J. and Stack, T.D.P. (1998) Ligand Self-Recognition in the Self-Assembly of a $[\{\mathrm{Cu}(\mathrm{L})\} 2] 2+$ Complex: The Role of Chirality. Angewandte 
Chemie International Edition, 37, 928-932.

https://doi.org/10.1002/(SICI)1521-3773(19980420)37:7<928::AID-ANIE928>3.0.C $\underline{\mathrm{O} ; 2-\mathrm{T}}$

[23] Hartshorn, C.M. and Steel, P.J. (1997) Self-Assembly and X-Ray Structure of a Ten-Component, Three-Dimensional Metallosupramolecular Cage. Chemical Communications, No. 6, 541. https://doi.org/10.1039/a608081b

[24] Hennigar, T.L., MacQyarrie, D.C., Losier, P., Rogers, R.D. and Zaworotko, M.J. (1997) Supramolecular Isomerism in Coordination Polymers: Conformational Freedom of Ligands in [Co(NO3)2(1,2-bis(4-pyridyl)ethane)1.5]n. Angewandte Chemie International Edition, 36972.

[25] Wang, Q.M., Guo, G.C. and Mak, T.C.W. (1999) A Coordination Polymer Based on Twofold Interpenetrating Three-Dimensional Four-Connected Nets of 42638 Topology, [CuSCN(bpa)] [bpa = 1,2-bis(4-pyridyl)ethane]. Chemical Communications, No. 18, 1849-1850. https://doi.org/10.1039/a905085j

[26] Kondo, M., Shimamura, M., Noro, S., Kimura, Y., Uemura, K. and Kitagawa, S. (2000) Synthesis and Structures of Coordination Polymers with 4,4'-dipyridyldisulfide. Journal of Solid State Chemistry, 162, 113.

[27] Tabellion, F.M., Seidel, S.R., Arif, A.M. and Stang, P.J. (2001) Discrete Supramolecular Architecture vs Crystal Engineering: The Rational Design of a Platinum-Based Bimetallic Assembly with a Chairlike Structure and Its Infinite, Copper Analogue. Journal of the American Chemical Society, 123, 7740-7741. https://doi.org/10.1021/ja015784a

[28] Wang, R., Han, L., Jiang, F., Zhou, Y., Yuan, D. and Hong, M. (2005) Syntheses and Crystal Structures of Copper(II) Coordination Polymers Comprising Discrete Helical Chains. Crystal Growth \& Design, 5, 251-256. https://doi.org/10.1021/cg034237t

[29] Aakeröy, C.B. and Seddon, K.R. (1993) The Hydrogen Bond and Crystal Engineering. Chemical Society Reviews, 22, 397-407. https://doi.org/10.1039/CS9932200397

[30] Jeffery, G.A. (1997) Introduction to Hydrogen Bonding. Wiley, Chichester.

[31] Atwood, J.L., Barbour, L.J. and Jerga, A. (2004) Angewandte Chemie International Edition, 432948.

[32] Sada, K., Tanaka, K.T., Tanaka, A., Epergyes, A., Nagahama, S., Matsumoto, A. and Miyata, M. (2004) Organic Layered Crystals with Adjustable Interlayer Distances of 1-Naphthylmethylammonium n-Alkanoates and Isomerism of Hydrogen-Bond Networks by Steric Dimension. Journal of the American Chemical Society, 126, 1764-1771. https://doi.org/10.1021/ja038379n

[33] Higashi, T. (1995) Program for Absorption Correction. Rigaku Corporation, Tokyo.

[34] (1997) SHELXTL, Version 5.1. Siemens Industrial Automation, Inc., Tokyo.

[35] Fifield, F.W. and Kealy, D. (2000) Principles and Practice of Analytical Chemistry. 5th Edition, Blackwell Science, Oxford, 378-393. 